\title{
DESISTIR NÃO É UMA OPÇÃO
}

\author{
GIVING UP IS NOT AN OPTION
}

FERNANDA MOOJEN LEMOS

Universidade do Vale do Itajaí - Univali

Especialização em Gestão Financeira

Orcid: http://orcid.org/0000-0002-8025-243X / E-mail: fernanda.moojen@gmail.com

\author{
MÁRIO ANTÔNIO SENSI FILHO \\ Universidade do Vale do Itajaí - Univali \\ Mestrando em Administração na UNIVALI \\ Orcid: http://orcid.org/0000-0002-2563-7513 / E-mail: mariosensi@icloud.com \\ Endereço: Rua das Azelias, n 583, Bairro Nossa Sra. da Paz. \\ Balneário Piçarras-SC - CEP 88380-000 \\ JEFERSON LANA \\ Universidade do Vale do Itajaí - Univali \\ Doutor em Administração. Professor do PPGA da UNIVALI \\ Professor do PPGA - UNIVALI \\ Orcid: http://orcid.org/0000-0002-9787-1114 / E-mail: jlana@univali.br
}

\begin{abstract}
RESUMO
Este caso para ensino tem como principal objetivo elucidar o aluno sobre o mercado de opções e algumas possíveis estratégias. Rafael, protagonista da história, reencontra um velho amigo de faculdade, João Paulo, o qual obteve grandes resultados investindo no mercado de opções, incomodado pela baixa rentabilidade de seus investimentos, Rafael inicia seu aprendizado e sua busca por atingir seus objetivos futuros seguindo as dicas do colega, porém encontra-se divido entre a possibilidade de grandes resultados e colocar em risco o dinheiro economizado para compra do seu apartamento. O presente caso de ensino utilizou informações reais do mercado financeiro para simular o primeiro investimento em opções de ações por Rafael, e se torna importante por retratar a dificuldade enfrentada por investidores frente a complexidade do mercado de opções, que acaba fazendo com que, apresente uma baixa liquidez para poucos ativos e acabe sendo pouco explorado no Brasil. Este material é indicado para alunos de graduação e pós-graduação, dentro da disciplina de mercado de capitais, que já tenham um prévio conhecimento do assunto.
\end{abstract}

Palavras-chave: Mercado de capitais. Derivativos. Mercado de opções .

\section{ABSTRACT}

This teaching case has as main objective to elucidate the student about the options market and some possible strategies. Rafael, the protagonist of the story, meets an old college friend, João Paulo, who obtained great results by investing in the options market, troubled by the low profitability of his investments, Rafael begins his learning and his quest to reach his future goals following the tips of the colleague, but is divided between the possibility of great results

Data de submissão: 19/04/2019. Revisão: 01/12/2019. Data de aceite: 04/02/2020. Data de publicação: 30/03/2020. 
and put at risk the money saved for purchasing his apartment. The present case used real information from the financial market to simulate Rafael's first investment in stock options, and becomes important for portraying the difficulty faced by investors in the face of the complexity of the options market, low liquidity to few assets and ends up being little explored in Brazil. This material is suitable for graduate and postgraduate students, within the discipline of stock markets, who already have a previous knowledge of the subject.

Keywords: Stock market. Derivatives. Stock options.

\section{UM REENCONTRO, MUITAS SURPRESAS}

Era uma sexta feira, novembro de 2017, Rafael Andrade estava em um restaurante badalado na cidade com sua noiva, Juliana, como costumavam fazer esporadicamente. Entre aperitivos e alguns copos de bebida avistou uma figura conhecida, era João Paulo, mais conhecido como "JP", um grande amigo da época de faculdade de engenharia civil, um companheiro de inumeras festas e que por sinal seu grande "legado" na faculdade foi ficar conhecido frequentar as aulas com uma tremenda ressaca.

Para a surpresa de Rafael, João Paulo estava muito bem vestido com um terno cinza, camisa branca e sapato social, muito diferente do chinelo de borracha e das bermudas de praia que costumava usar. Sua curiosidade e espanto chegaram ao ponto de chamar atenção da sua noiva, que inclusive quis entender o motivo de tamanha reação, Rafael então descreveu resumidamente o perfil do "JP" durante o faculdade e logo em seguida decidiu abordar o ex-colega:

- Com licença, Sr. João Paulo, poderia me conceder um minuto da sua atenção? Disse Rafael em tom irônico, para chamar atenção do seu ex-colega de faculdade:

- Rafa, meu camarada! Há quanto tempo meu amigo, muito bom te rever. Como estão as coisas?

Durante alguns minutos ambos tentaram resumir suas histórias pós- faculdade. Foi então que João Paulo descreveu sua trajetória por uma grande multinacional, do setor farmaceutico, desde o estágio até a posição atual, coordenador financeiro. Mas Rafael também estava no mercado, e sabia que mesmo em um cargo de coordenador, o salário não seria o bastante para tamanha transformação, foi então que ele continuou sua "entrevista":

- Não esconde o jogo JP, tu é coordenador financeiro mesmo ou já é sócio? - Disse Rafael rindo, ainda insatisfeito com as respostas que vinha obtendo:

- Então, Rafa, na verdade minha mudança de patamar foi mesmo quando comecei a operar ações e derivativos, me apaixonei pelo mercado financeiro, tive algumas perdas no começo, mas fiz cursos, me aprofundei e hoje fiz disso minha profissão. Pessoalmente gosto de especular no mercado através das opções, mas em parte do meu patrimônio adotei algumas estratégias que me permitem proteger e remunerar meus investimentos, na empresa que trabalho inclusive utilizo contratos derivativos cambiais para proteção das negociações internacionais.

Rafael ficou ainda mais surpreso com a resposta que obteve, mercado financeiro? Ele ainda estava tentando digerir tanta informação:

- Que legal JP! Sou leigo no assunto, tenho conta em uma corretora de ações, mas até hoje só investi em renda fixa mesmo. A emoção e volatilidade do mercado me deixam inseguro, não sei se tenho "estômago" para este tipo de investimento.

- Você não está sozinho meu amigo. A sua preocupação é muito comum, e digo mais, é importante, o mercado é cheio de autodidatas do Youtube que acham que são traders e 
perdem muito dinheiro com isso. Inclusive o mercado de opções tem algo digamos que, sedutor, porque você pode alavancar muito seu capital, por esse motivo tens que entender, mensurar, o risco de cada operação, porque caso contrário Rafa, tudo "vira pó". - Falou JP rindo, mas como viu que Rafael não entendeu a piada, complementou:

- É um termo do mercado de opções quando a opção que você comprou não é exercida, ela deixa de existir. Tem muita coisa no mercado de opções, desde especulação simples até operações menos arriscadas, como a remuneração de carteira por exemplo.

Por fim, Rafael, fingiu que entendeu tudo aquilo que acabara de ouvir e percebendo a impaciência da sua noiva, encerrou a conversa convidando JP para uma janta, com objetivo de conversarem mais, relembrarem bons momentos. Depois de uma calorosa despedida (ocasionada pelo nível de álcool no sangue dos dois) Rafael passou seu e- mail para JP, que ficou então de lhe enviar alguns materiais sobre o mercado de ações e opções. Toda a conversa despertou a uma enorme vontade de aprender mais sobre o mercado financeiro.

Desde que noivou com Juliana as prioridades de Rafael mudaram, ao invés do carro novo do ano, vem pensado em um apartamento de dois quartos, premissa da vida de casado. Nesse sentido sabia que precisaria mudar suas estratégias de investimento e o encontro com João Paulo lhe deu um novo ânimo para investir.

Naquela noite, Rafael não conseguiu dormir direito, as palavras de JP ecoavam na sua mente, o que ele quis dizer com remunerar a carteira? Seria realmente possível controlar o risco investindo em ações e opções? Como faria isso?

\subsection{DE POUPADOR A INVESTIDOR}

Vindo de uma família de classe média, Rafael não teve muito que reclamar, mas sempre teve em si a ânsia de ser diferente, de fazer mais que a maioria. Tal determinação o garantiu a promoção a sócio do escritório de engenharia que trabalhava, após três anos da sua contratação como estagiário. Junto com a promoção veio a tão sonhada estabilidade, que para o seu pai era motivo de muito orgulho. Sr. Alberto, pai de Rafael, foi funcionário público, hoje aposentado, sempre incentivou Rafael aos estudos e a busca pelo equilíbrio financeiro desde pequeno, através das "mesadas", criou em Rafael a rotina de poupar uma parte de seu salário.

Quando completou 21 anos Rafael recebeu algum dinheiro de um fundo de previdência privada que seu pai havia contribuído desde seu nascimento, neste momento começou sua jornada em se tornar um investidor ao invés de um mero poupador. Naquela época, 2006, a Selic (taxa básica de juros no Brasil) estava em média 15,75\% a.a., os juros de poupança descontados a inflação 4,92\% a.a., panorama perfeito para um investidor em busca de uma boa remuneração do seu capital com baixo risco, o investimento em títulos públicos.

Por influência de seu pai, Rafael aplicou o capital que possuía em um título do Tesouro Direto indexado à taxa Selic, hoje, novembro de 2017, com mais alguns aportes e investimentos tem um capital de $\mathrm{R} \$ 50.000,00$. Parecia um bom montante, porém não era suficiente para atingir seu objetivo de comprar um imóvel. Após a conversa com João Paulo, percebeu que poderia ter multiplicado este valor se tivesse investido uma parcela do seu capital em renda variável.

Era sábado de manhã, Rafael recebeu uma notificação no celular de uma nova mensagem na caixa de entrada, era um e- mail de João Paulo. Ficou surpreso, não esperava que JP lembraria de lhe enviar os materiais sobre investimentos em opções que havia prometido, ele não costumava lembrar nem o dia da semana na época da faculdade. 
O colega começou o e- mail enfatizando com muito bom humor (e um certo excesso de auto estima) seus grandes ganhos com ações, os 700 \% de lucro adquiridos em duas semanas de uma operação com opções, e outros relatos que para Rafael soavam impossíveis de acreditar.

Após aproximadamente vinte linhas de enaltecimento, JP finalmente começou a elucidar sobre o funcionamento do mercado de opções. Primeiramente explicou que as opções fazem parte do mercado de derivativos, ou seja, algo que deriva de um ativo, uma ação por exemplo. Também descreveu que existem dois tipos de opções, uma delas era chamada de CALL, que são opções de compra de determinado ativo em uma data específica e com um preço pré- estabelecido, e a outra de PUT, que são opções de venda de determinado ativo em uma data específica e com um preço pré- estabelecido. Também enfatizou que toda terceira segunda feira de cada mês estas opções expiravam.

No e- mail, João Paulo também explicou como são formados os códigos das opções. Por exemplo PETRK20, as primeiras quatro letras referem- se à ação objeto daquela opção. A quinta letra é o mês de vencimento da opção. E os dois últimos números fazem referência ao valor de exercício de uma opção, ou strike, ainda que nem sempre os valores sejam iguais.

Quadro 1 - Nomenclatura das Opções

\begin{tabular}{|c|c|c|}
\hline Mês de vencimento & Opções de CALL & Opções de PUT \\
\hline Janeiro & A & M \\
\hline Fevereiro & B & O \\
\hline Março & C & P \\
\hline Abril & D & Q \\
\hline Maio & E & R \\
\hline Junho & F & S \\
\hline Julho & G & T \\
\hline Agosto & H & U \\
\hline Setembro & I & V \\
\hline Outubro & J & W \\
\hline Novembro & K & X \\
\hline Dezembro & L & \\
\hline
\end{tabular}

Fonte: ADVFN

Além disso, o e- mail continha um anexo sobre compra e venda de opções (Anexo 1). Após ler e reler as informações contidas no e- mail de JP, Rafael ficou empolgado para investir em opções. Ainda que um pouco cético em relação ao ganhos relatados pelo seu colega, mas percebeu que poderia ser uma boa forma de alavancar seu capital, porém com risco controlado.

Tudo isso para desgosto de seu pai, que escutava as suas considerações durante o almoço de domingo em família aterrorizado. Sr. Alberto sempre defendia que quem investia em ações era "louco", que era coisa para grandes investidores especuladores, :

- Investir em ações é como jogar na loteria meu filho, puro jogo de azar! É impossível saber que rumo o mercado irá tomar amanhã. E o pior, a ilusão de um ganho hoje, faz você perder até o que você não tem amanhã. Prefiro ficar com meu dinheiro na segurança da renda fixa, assim não me preocupo. Filho, não vá se meter nisso, preze por tudo que economizou.

Rafael tentara argumentar com seu pai, mas viu que seu esforço era em vão, Sr. Alberto nunca mudaria o pensamento conservador, durante sua vida ele havia conhecido muitas pessoas que realmente haviam perdido além do que tinham, do dia para a noite. E mesmo contra as orientações de seu pai, ele estava decidido em dar uma chance ao mercado, ou na verdade tentar uma chance no mercado, iria investir em opções. 


\subsection{A PRIMEIRA VEZ A GENTE NÃO ESQUECE}

Na primeira hora da manhã de segunda feira, 6 de novembro, Rafael tomou um café forte e puro, como gostava, abriu seu notebook, e começou a pesquisar sobre os ativos os quais as opções poderiam ser negociadas. Descobriu que os papéis com maior liquidez eram basicamente dois, Petrobras e Vale do Rio Doce. Pensou que deveria escolher uma empresa para estudar e se aprofundar mais, sendo assim decidiu que investiria em Petrobras.

Em sua pesquisa observou que a análise técnica era muito utilizada pelos investidores em opções, principalmente para avaliar e identificar a tendência do ativo, de alta ou de baixa, bem como seus pontos de resistência e suporte. Baixou em seu computador o gráfico de PETR4 e resolveu observa- lo, mesmo com o pouco conhecimento que tinha na analise gráfica.

Naquele dia as ações da Petrobras (PETR) estavam cotadas a $R \$ 17,30$, o que no mercado de opções se utilizava o termo SPOT, para definir o preço atual de um ativo. Observando o gráfico lhe pareceu um bom negócio comprar uma opção de compra (CALL) pois o ativo estava em tendência de alta.

Figura 1 - Gráfico candlestick de cotação do ativo PETR4 em 2017 com linha de tendência de alta.

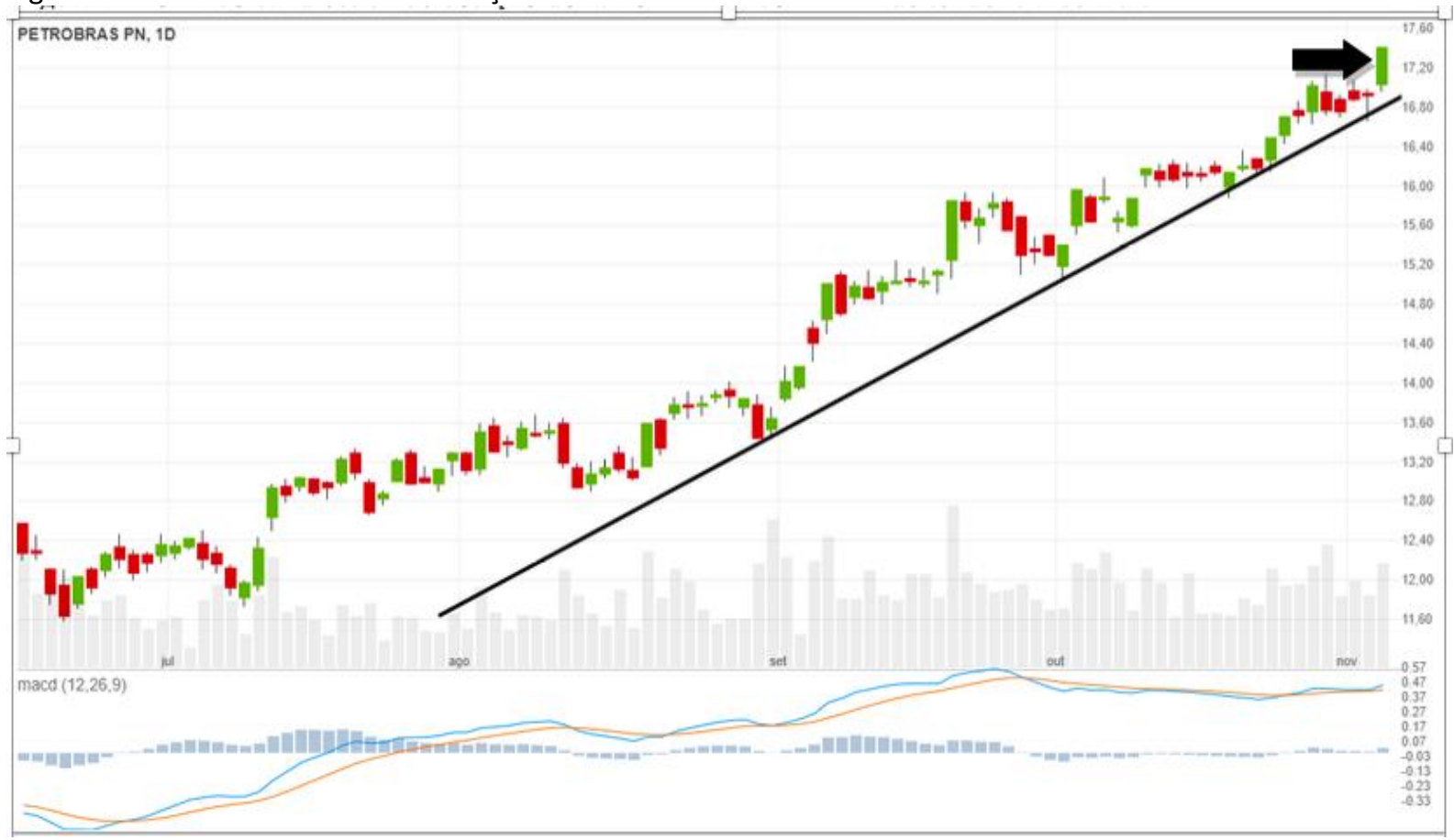

Fonte: ADVFN

Além disso os noticiários evidenciavam a recuperação da empresa após um período de recessão, ele acreditava que havia espaço para valorização do papel, que no seu auge já chegou a passar dos quarenta reais.

Tabela 1 - Panorama Petrobras.

\section{Petrobras, Vale e Siderúrgicas saltam até $6 \%$.}

A ação da Petrobras subiu forte na esteira da forte alta do petróleo no mercado internacional em meio ao expurgo na Arábia Saudita. A commodity negociou nos maiores patamares desde 2015 após ação anticorrupção na Arábia Saudita, que pode fortalecer o poder do príncipe Mohammed bin Salman, favorável a cortes de produção pela Opep.

As ações mais indicadas para novembro, segundo 17 corretoras.

As ações da Petrobras (PETR4) lideram as recomendações de corretoras a investidores para novembro. Elas foram sugeridas em 13 das 17 carteiras de ações recebidas por EXAME este mês.

Fonte: Infomoney e Exame, seu dinheiro. 
Após reunir as informações, Rafael se sentiu mais confiante e até um pouco eufórico com todo esse novo mundo que acabara de descobrir e resolveu buscar os contratos de opções de CALL que estavam em negociação para o próximo exercício que seria dia 21 de novembro excepcionalmente devido ao feriado no dia anterior:

Quadro 2 - Opções de Petrobras em 2017.

\begin{tabular}{|c|c|c|c|}
\hline CALL & TIPO & STRIKE & PREÇO \\
\hline PETRK19 & Americana & 19,00 & 0,15 \\
\hline PETRK185 & Americana & 18,50 & 0,25 \\
\hline PETRK18 & Americana & 18,00 & 0,39 \\
\hline PETRK17 & Americana & 17,50 & 0,58 \\
\hline PETRK9 & Americana & 17,00 & 0,83 \\
\hline PETRK46 & Americana & 16,50 & 1,15 \\
\hline PETRK26 & Americana & 16,00 & 1,52 \\
\hline PETRK45 & Americana & 15,50 & 1,93 \\
\hline PETRK150 & Americana & 15,00 & 2,38 \\
\hline
\end{tabular}

Fonte: Elaborado pelos autores

Apesar de ainda estar com algumas dúvidas, resolveu comprar a opção PETRK185. O preço de $\mathrm{R} \$ 0,25$ por opção lhe pareceu oportuno, compraria 10.000 opções de call por $\mathrm{R} \$ 2.500,00$, se o preço da ação atingisse o strike almejado poderia tanto exercer a opção no dia 21 ou então vender a opção e obter o lucro antes da data do exercício. Se estivesse adquirindo o ativo no mercado a vista teria que desembolsar $\mathrm{R} \$ 173.000,00$, o poder de alavancagem era impressionante.

No dia seguinte da compra Rafael teve um dia ocupado no escritório e não pode acompanhar o mercado, quando chegou em casa foi conferir como estava seu investimento. Levou um susto ao abrir o home broker, as ações PETR4 abriram em queda, naquele momento já começou a questionar sua decisão de compra. Durante aquela semana não houve melhora, o ativo continuou a cair na bolsa e na sexta feira a opção de Rafael já estava custando $R \$ 0,07$. Ao consultar um site de notícias voltado para investidores, se deparou com um resumo do dia no mercado financeiro.

Tabela 2 - Queda das ações da Petrobras.

\section{Bolsa cai 2,55\%, maior queda em quase 6 meses; Petrobras e BB tombam 5\%.}

O Ibovespa, principal índice da Bolsa brasileira, fechou esta terça- feira (7) em baixa de 2,55\%, a $72.414,88$ pontos, após duas altas seguidas. Na véspera, a Bolsa subiu $0,53 \%$. Essa é a maior queda percentual diária desde 18 de maio, logo após a divulgação das gravações da JBS, quando o índice caiu 8,8\%. É também o menor nível fechamento desde 5 de setembro. Entre as maiores quedas do dia, as ações preferenciais da Petrobras despencaram 5,34\%. Os papéis ordinários da estatal perderam 4,59\%.

Fonte: Uol Economia (2017).

A última semana do exercício foi intensa para os investidores da Petrobras, período o qual seriam divulgados os resultados do terceiro trimestre de 2017. As perspectivavas eram muito boas para a companhia, porém mesmo apesar dos números terem sido positivos ficaram aquém da expectativa do mercado e toda essa frustação foi refletida no preço do ativo da companhia. Rafael ficou apreensivo e desanimado, considerando uma possível reversão de tendência de alta do ativo. Logo que terminou de digerir tudo que havia acontecido, a imagem do seu pai o desencorajando a entrar nesse mercado veio a sua mente. Rafael havia começado com o pé esquerdo. 
Figura 2 - Gráfico candlestick de cotação do ativo PETR4 em 2017 com quebra da linha de tendência de alta.

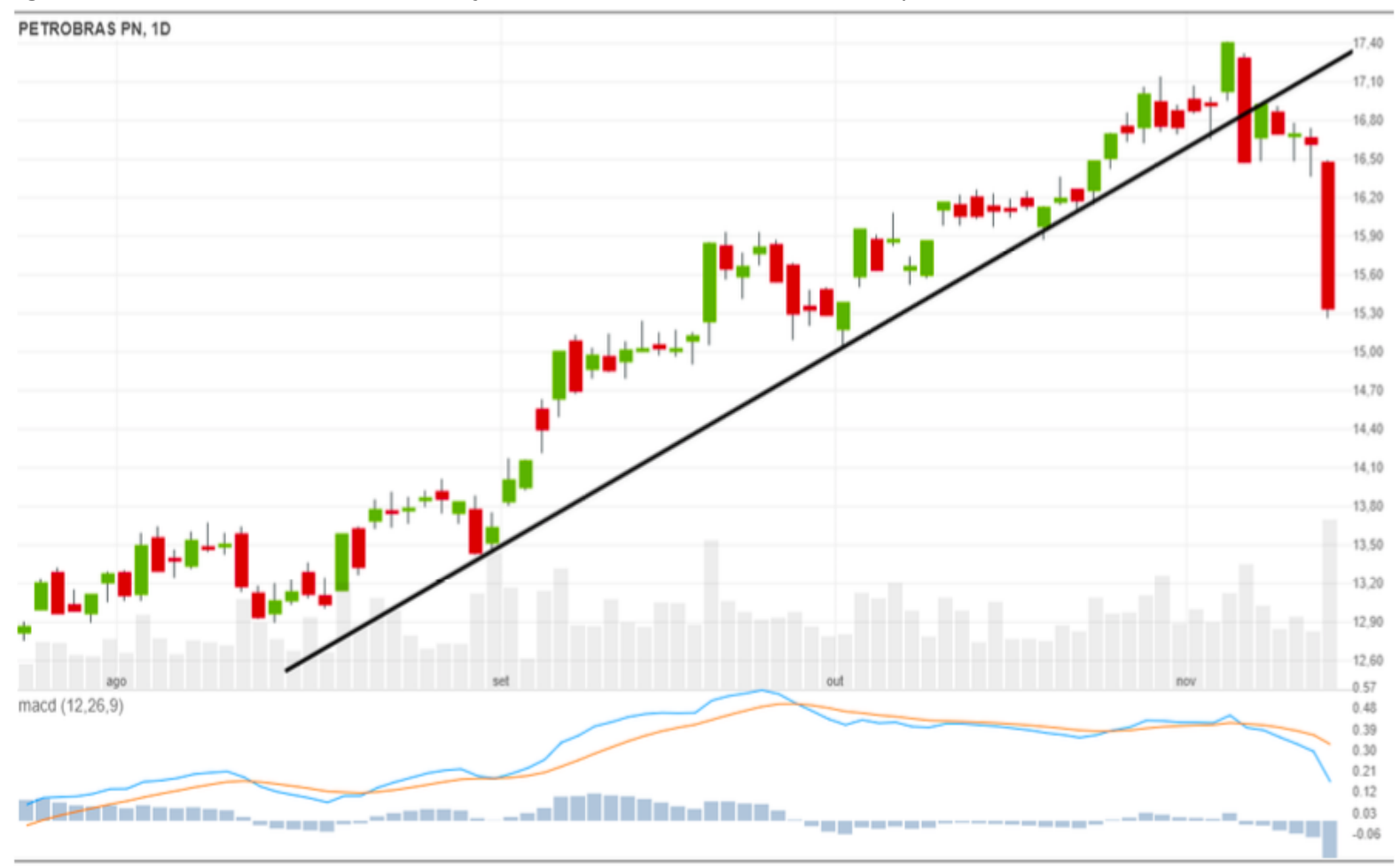

Fonte: ADVFN

Nos próximos dias que antecederam o exercício da opção, Rafael não abriu seu home broker, no dia 21 de novembro no primeiro horário de abertura das negociações da bolsa resolveu conferir seu resultado. Nesta hora aceitou a derrota, as ações de Petrobras estavam cotadas $R \$ 16,12$, ou seja, sua opção virou pó e ele havia perdido os $R \$ 2.500,00$ que havia investido, a frase de seu pai "jogo de azar" visitou novamente seus pensamentos.

Se fossem outros tempos, insistiria nas compras de CALL a seco, termo utilizado quando a compra da opção era feita por alguém que não detinha o ativo correspondente, mas a pressão do casamento e das dívidas que viriam em seguida o desestimularam. Resolveu que não queria mais operar sem que estivesse bem decidido e claro, com mais informações, mas neste turbilhão de cortisol uma notícia Ihe chamou muita atenção.

Quadro 4-Compra de Put.

Mercado de opções: investidor que "apostou" em balanço ruim da Petrobras lucrou até $750 \%$.

Enquanto as ações da Petrobras caíram até $8 \%$ após a divulgação do resultado do 30 trimestre, várias "puts" (opções de venda) negociadas na Bovespa dispararam mais de $500 \%$ no dia.

Fonte: Infomoney (2017).

Será mesmo que era preciso "apostar" para se obter lucro? Mas e as estratégias de que JP lhe falou, é possível mesmo alcançar um percentual de $700 \%$ como ele havia mencionado? Existiria outra forma de investir em opções se não por meio de especulação?

Naquele momento pensou em João Paulo, precisava conversar com ele, descobrir seus segredos para investir. Lembrou o nome da firma em que ele trabalhava e em uma busca rápida pela internet, achou o telefone da recepção. A atendente disse que ele estava uma reunião, mas assim que disponível retornaria. Passados trinta minutos o telefone de Rafael chamou:

- Oi Rafa! Como anda por aí? Que bom que me ligou. 
- Oi JP! Por aqui tudo bem, quer dizer, li os materiais que você me enviou e tentei me aprofundar mais no mercado financeiro, por fim acabei comprando algumas CALL de Petrobras na expectativa de que as ações iriam subir conforme os analistas esperavam, mas foi exatamente ao contrário, minha opção virou pó. Fiquei bem receoso com os investimentos em opções, aliás vi algumas manchetes do pessoal que comprou opções de PUT e lucraram muito.

- Bom, renda variável é assim mesmo, temos que estar preparados para perdas e ganhos, cada operação nos deixa mais experientes. As opções se beneficiam muito da volatilidade do ativo, quanto mais rápido as ações caem ou sobem maiores são os "prêmios" que as opções pagam. Em qualquer investimento o fator principal é tornar os ganhos muito maiores do que as perdas, para isso temos estratégias de investimento, podemos ganhar dinheiro tanto na alta quanto na baixa do mercado, que foi o caso do pessoal que "apostou" que as ações da Petrobras iam cair e acabaram ganhando muito dinheiro. Os investidores que lucraram poderiam ter tanto comprado opções de PUT como vendido opções de CALL.

- Mas, JP, você sabe que logo vou casar e estou pensando em comprar um apartamento, além disso não tenho muito tempo para acompanhar o mercado. Preciso de uma estratégia mais assertiva e com pouco risco - Logo após terminar a frase, Rafael percebeu que havia falado uma loucura, se houvesse algo assim, fácil, não haveria investidor falido, mas continuou se raciocínio. - Algo que eu possa continuar investindo em renda variável porém com mais tranquilidade e menos "afobamento".

- Neste caso Rafa, você pode continuar utilizando as opções, não para alavancar seu capital, mas para protege- lo. Caso tenha ações em carteira você pode remunerar suas ações mês a mês, sem necessariamente precisar vende-las, isso se chama venda coberta ou remuneração de carteira. Você fez uma operação de compra a seco que é o mais básico em opções, mas esta é apenas uma das diversas estratégias operacionais disponíveis. Sugiro que você compre um lote de PETR4 para aproveitar o declínio do preço da ação e...

Sem nem terminar sua frase, João Paulo se despediu alegando ter outra ligação em espera deixando Rafael mais atordoado. Ainda tinha muitas dúvidas que não conseguiu esclarecer com a breve conversa, JP agora havia lhe passado mais informações, porém não a "fórmula mágica" que estava esperando.

Sua ânsia em ganhar dinheiro foi tomada por cautela, precisava controlar suas emoções e se aprofundar na dinâmica das opções e nas estratégias disponíveis, mas ao mesmo tempo decidiu seguir a sugestão de JP e comprou as ações da Petrobras no mercado a vista. Após novamente ter tomado outra decisão por ousada e por impulso, decidiu tirar um tempo para tentar esfriar a cabeça e definir o próximo passo.

\subsection{A ESTRAGÉGIA INFALÍVEL}

Naquele final de ano Rafael conseguiu se programar para tirar vinte dias de férias, principalmente devido a insistência de Juliana, que reclamava das longas horas trabalhadas pelo noivo e queria que planejassem juntos os detalhes do casamento, ainda mais próximo.

Em uma tarde qualquer de dezembro foram a uma loja de departamentos para escolher a lista de presentes do casamento. Enquanto Rafael estacionava o carro, Juliana foi entrando na loja, neste meio tempo João Paulo guardava compras em um veículo no mesmo estacionamento. Rafael não sabia se o cumprimentava ou seguia em diante, sabia que ele o perguntaria sobre seus investimentos, ainda estava comprado em ações da Petrobras mas não tinha mais feito nenhuma operação.

Antes que tivesse tempo para decidir o que fazer, João Paulo se aproximou: 
- E ai sumido! Não me deu mais notícias, fiquei esperando seu retorno após nossa última conversa. Tenho boas notícias, venho analisando os papéis da Petrobras e acredito que irão entrar em um novo período altista, uma boa oportunidade para colocar em prática a estratégia que eu havia lhe comentado, de remuneração da carteira, através da venda coberta de CALL. Você comprou os ativos?

- É, bom, comprei um lote de 1.000 ações de PETR4, mas ainda não estou seguro em utilizar as opções, acho que vou manter minhas ações no longo prazo sabe, li algo sobre o "buy and hold", talvez aproveitar as oscilações para comprar mais, com o casamento chegando não posso colocar mais dinheiro em jogo. - Disse Rafael sem conseguir disfarçar a frustação e insegurança em sua voz:

- Rafa, não desanima, não! Quem está no "mercado" é para se molhar amigo. Pelo seu perfil, a remuneração de carteira é mais adequada mesmo. Você pode utilizar o "buy and hold" e ainda ter uma remuneração mensal da sua carteira. Todo mês você vende opções de compra call na mesma proporção da carteira, o preço de strike precisa ser fora do dinheiro. Hipoteticamente falando, se o preço das ações hoje estão $R \$ 15,00$ e está comprado em 1.000 ações, você vende 1.000 contratos de call a $R \$ 17,00$, recebe com a venda um prêmio $R \$ 0,40$ por ação e se na data do exercício a ação estiver a $R \$ 16,00$, as opções viram pó, você embolsa os $R \$ 0,40$ e ainda continua com as ações. Caso isso aconteça, você refaz a operação, agora com uma opção que vence no mês seguinte. Porém se na data do exercício a ação estiver cotada a um valor maior que o strike, a opção será exercida e você usa o seu ganho para comprar outro lote e continuar a estratégia. É ganho na certa! - Afirmou João Paulo com empolgação.

Parecia uma boa estratégia, mas Rafael não colocaria tudo a perder novamente, aproveitaria os últimos dias de férias para analisar a estratégia sugerida, estava mais experiente agora, sabia suas fraquezas e o que precisaria melhorar para ser bem sucedido, disse para João Paulo que pensaria no assunto e foi ao encontro da noiva.

Mas e agora, qual seria o próximo passo de Rafael? Se aventuraria novamente no mercado de opções? Será que realmente essa nova estratégia apresentada por JP é realmente mais segura? Estava em jogo não somente as suas economias, mas seu relacionamento, pois o capital investido deveria ser utilizado para compra do apartamento do casal. Será que realmente existe "ganho certo" no mercado de opções? Naquele momento só lhe vinha uma ideia na cabeça: Desistir não é uma opção

\section{ANEXO 1}

\section{COMPRA E VENDA DE OPÇÕES (Calls e Puts)}

Opções são instrumentos que conferem a seus titulares o direito de comprar (Call) ou vender (Put) um ativo em uma data futura por um preço predeterminado. Um investidor pode comprar ou vender Calls ou Puts para fins especulativos ou de hedge. Desconsiderando outros fatores que impactam a precificação das opções, Calls ficam mais caras à medida que o ativo base se valorize, enquanto Puts se beneficiam de um cenário de queda. 
Figura 3: Gráficos de Compra de Call e Compra de Put
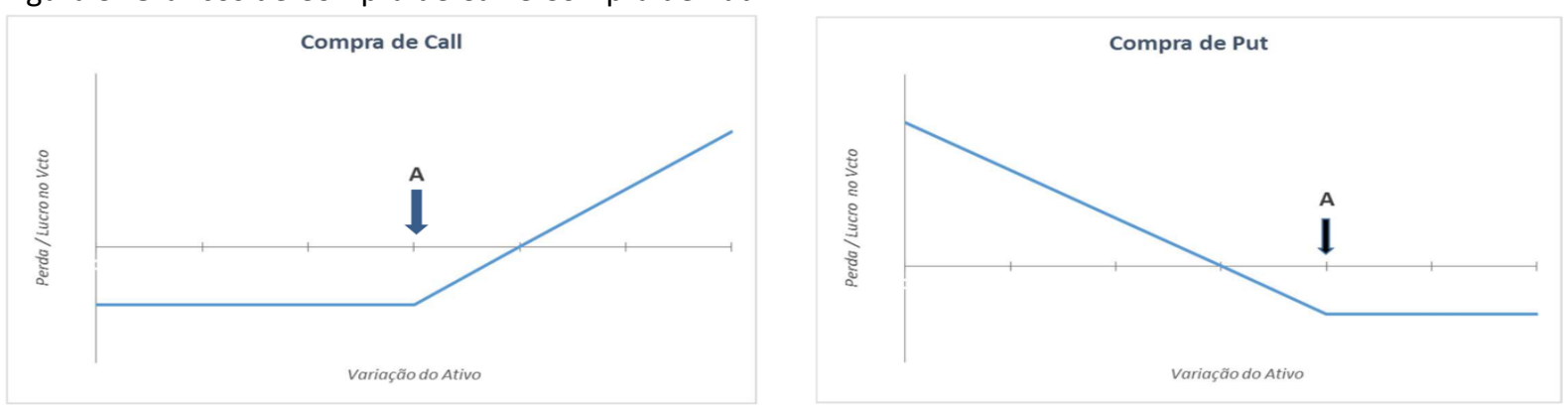

Fonte: XP Investimentos.

Como funciona a Compra de Call:

O investidor que compra uma call1 tem o direito de comprar o ativo objeto pelo strike3 predeterminado (ponto A). No vencimento, exercerá o seu direito apenas se o ativo estiver negociando acima do strike - do contrário, será mais vantajoso comprar o ativo à mercado. $\mathrm{A}$ compra da call pode ter fins especulativos, quando o viés é de alta mas o investidor não gostaria de comprar o ativo, ou para fins de hedge.

Características: a) Viés de Alta, b)Ganho Máximo: llimitado (Preço final - A - prêmio), c) Perda Máxima: prêmio gasto na compra da opção, d) Não há chamada de margem.

Como funciona a Compra de Put:

O investidor que compra uma put tem o direito de vender o ativo objeto pelo strike predeterminado (ponto A). No vencimento, exercerá o seu direito apenas se o ativo estiver negociando abaixo do strike - do contrário, será mais vantajoso vender o ativo à mercado. $\mathrm{A}$ compra da put pode ter fins especulativos, quando o viés é de baixa, ou para fins de hedge, quando há a necessidade de proteção contra a queda do ativo.

Características: a) Viés de Baixa • Ganho Máximo: A - prêmio - preço final, b) Perda Máxima: prêmio gasto na compra da opção, c) Não há chamada de margem.

\section{NOTAS DE ENSINO}

\subsection{OBJETIVOS EDUCACIONAIS}

Este caso para ensino tenta desmistificar um pouco o mercado de opções, assunto geralmente não abordado durante as disciplinas que tratam do mercado financeiro. Sua recomendação é para alunos de graduação e pós-graduação, particularmente para a disciplina de mercado de capitais que venha a ser contemplada nos cursos de administração, economia, ciências contábeis e comércio exterior.

Tendo em vista a complexidade do mercado financeiro, principalmente opções de ações, e a dificuldade em se abordar a prática em sala de aula, o objetivo principal deste caso foi simular uma situação real de operação em opções de ações, proporcionando ao aluno a aproximação a este tipo de investimento.

Para obtenção de um melhor aproveitamento dos temas abordados, é recomendável que o aluno tenha conhecimento básico do funcionamento do mercado de financeiro, mais precisamente a respeito de Opções e suas terminologias.

Ao final da aplicação deste caso para ensino, espera-se alcançar os seguintes objetivos educacionais:

a) elucidar sobre os principais termos e funcionamento do mercado de opções;

b) o poder de alavancagem proporcionado pelas operações de opções a seco 
c) a possibilidade de realizar estratégias de investimento que protegem o capital;

\subsection{FONTE DE DADOS}

Toda história, personagens e cenários utilizados na construção deste caso para ensino, são fictícios. Porém também utilizou-se de dados reais, secundários, no que tange as informações, terminologias e conceitos do mercado financeiro.

Os dados secundários foram extraídos de documentos e artigos de sites especializados no mercado financeiro, como o ADVFN Brasil, UOL Economia e XP Investimentos além do portal da B3, única bolsa de ativos no Brasil.

\subsection{PLANO DE AULA SUGERIDO}

Este caso foi desenvolvido pressupondo o conhecimento prévio dos alunos nos assuntos aqui abordados. Primeiramente sugere-se a leitura e resolução das questão elaboradas, em grupos 3 alunos, esse processo fará com que os alunos busquem mais informações sobre o assunto e aumente sua familiriadade com o tema.

Em seguida, o professor deverá discutir, de forma ampla, as respostas dos grupos, mediandos pontos e contrapontos, com objetivo de nivelar o entendimento do grande grupo, cabendo inclusive maiores explicações da parte operacional desse tipo de negiciação, se assim o professor entender que é válido e viável.

Por fim, ainda em grupos, pedir que pesquisem por alguma outra estratégia que possa ser utilizada para negociação com opções, a qual não tenha sido tratada neste caso. Após a pesquisa solicitar que cada grupo apresente uma estratégia, inclusive com simulações baseadas em cotações e cenários reais, cabendo o professor definir o ativo e período.

Quadro 3 - Plano de aula indicado

\begin{tabular}{|l|l|}
\hline Atividade & Tempo sugerido \\
\hline Leitura individual do caso de ensino & 45 minutos \\
\hline Separação da turma em grupos e resolução das questões propostas & 45 minutos \\
\hline Debate da turma relacionado às resoluções de cada grupo. & 30 minutos \\
\hline Pesquisa por e apresentação de alguma outra estratégia de Opções & 45 minutos \\
\hline Avaliação das soluções alternativas e discussão & 30 minutos \\
\hline
\end{tabular}

Fonte: Os autores.

\subsection{QUESTÕES SUGERIDAS AO PROFESSOR PARA DISCUSSÃO EM AULA}

1. Em sua primeira operação com opções, Rafael escolheu comprar opções de CALL ao invés de PUT. Por que ele tomou esta decisão?

2. Dentre os contratos de opções de CALL estudados por Rafael, quais estão dentro do dinheiro, fora do dinheiro e no dinheiro no momento em que ele efetuou a compra? Justifique sua resposta calculando os valores intrínsecos e extrínsecos de cada opção.

3. Considerando a estratégia de remuneração da carteira de ações apresentada por João Paulo, por que ele sugere a Rafael que escolha strikes fora do dinheiro?

4. Ao analisar a estratégia recomendada podemos afirmar que a compra de determinado ativo e a venda de uma opção de call do mesmo ativo seria o mesmo que vender uma opção de put? Porque seria mais interessante criar a opção de put sinteticamente do que comprala no mercado? 


\subsection{RESOLUÇÕES SUGERIDAS}

Questão 1: Em sua primeira operação com opções, Rafael escolheu comprar opções de CALL ao invés de PUT. Por que ele tomou esta decisão?

Em sua primeira operação com opções, Rafael escolheu comprar opções de compra (call) ao invés de opções de venda (put) após analisar graficamente a evolução dos preços da ação da Petrobras, os quais apontavam para um período de alta, o que foi corroborado pelas notícias que assinalavam um bom período da empresa. De acordo com Garner e Brittain (2009), uma opção de compra fornece ao titular o direito de adquirir o ativo em uma data específica e por um preço estipulado. Já uma opção de venda fornece ao titular o direito de vender o ativo em uma data específica e por um preço estipulado. O preço no contrato é chamado de preço de exercício ou strike price e a data é denominada data de expiração ou vencimento.

Para Azevedo (2010) o motivo pelo qual o investidor compra uma opção de call é que o mesmo visa um cenário positivo, desta forma seu objetivo é alavancar o possível resultado positivo com o aumento do preço da ação objeto, ou realizar um hedge para uma posição anteriormente vendida na ação.

As opções de compra e venda também se diferenciam em seu resultado. As opções de compra se tornam mais valiosas ao passo que o preço da ação aumenta e menos valiosas conforme o preço de exercício aumenta. Já em uma opção de venda, o resultado de exercício é o montante que o preço de exercício excede o preço da ação. Pode-se chegar à conclusão que as opções de venda reagem de forma contrária às de compra (HULL, 2016).

Questão 2: Dentre os contratos de opções de CALL estudados por Rafael, quais estão dentro do dinheiro, fora do dinheiro e no dinheiro no momento em que ele efetuou a compra? Justifique sua resposta calculando os valores intrínsecos e extrínsecos de cada opção.

Uma opção de call pode ser classificada como dentro do dinheiro quando o preço do ativo é maior que o preço do exercício, e uma opção de put está dentro do dinheiro quando o preço do ativo é menor que que o preço do exercício, produzindo nos dois casos um fluxo de dinheiro positivo. Já uma opção de call que está fora do dinheiro significa que o preço do ativo é menor que o preço do exercício, ninguém irá exercer o direito de comprar o ativo pelo preço de strike se seu valor de mercado é menor. Uma opção de put está fora do dinheiro quando o preço do ativo é maior que o preço do exercício. As opções estão no dinheiro quando o preço do ativo e o preço do exercício são iguais (BODIE; KANE; MARCUS, 2014).

$\mathrm{Na}$ intenção de se aprofundar a análise das terminologias das opções é importante ainda abordar a definição de valor intrínseco. O valor intrínseco de uma opção é estabelecido como o máximo de zero e o valor que a opção teria caso fosse exercida instantaneamente. Em uma opção de call, o valor intrínseco é, portanto, máx. (A $-E, 0)$, para uma opção de put máx. $(E-A, 0)$. Uma opção Americana dentro do dinheiro deve valer pelo menos o seu valor intrínseco porque o comprador pode receber o valor intrínseco exercendo a opção imediatamente. Geralmente o ideal para o comprador de uma opção Americana dentro do dinheiro seria esperar ao invés de exerce-la imediatamente, podemos afirmar então que a opção tem valor no tempo. O valor total de uma opção pode ser definido então como a soma de seu valor intrínseco e de seu valor no tempo (HULL, 2017).

Dentre os contratos de opções de call pesquisados por Rafael, fica evidente a distinção entre os contratos dentro do dinheiro, no dinheiro e fora do dinheiro. Como a ação objeto encontrava-se naquele momento cotada a $\mathrm{R} \$ 17,30$, todos os contratos com preço abaixo 
deste valor podem ser considerados dentro do dinheiro, assim como os contratos com o preço de exercício acima deste valor fora do dinheiro. Neste panorama a opção que mais se encontra no dinheiro seria a PETRK17, cotada a $R \$ 17,50$.

Quadro 4 - Preço do ativo objeto

\begin{tabular}{|l|c|c|c|c|c|}
\hline \multicolumn{7}{|c|}{ CALL } & $\begin{array}{c}\text { PREÇO DO } \\
\text { EXERCÍCIO (E) }\end{array}$ & PRÊMIO (P) & $\begin{array}{c}\text { VALOR } \\
\text { INTRÍNSECO } \\
\text { (A - E) }\end{array}$ & $\begin{array}{c}\text { VALOR DO } \\
\text { TEMPO } \\
(\mathbf{P}-\text { VI) }\end{array}$ & DEFINIÇÃO \\
\hline PETRK19 & 19,00 & 0,15 & & 0,15 & FORA DO DINHEIRO \\
\hline PETRK185 & 18,50 & 0,25 & & 0,25 & FORA DO DINHEIRO \\
\hline PETRK18 & 18,00 & 0,39 & & 0,39 & FORA DO DINHEIRO \\
\hline PETRK17 & 17,50 & 0,58 & & 0,58 & NO DINHEIRO \\
\hline PETRK9 & 17,00 & 0,83 & 0,30 & 0,53 & DENTRO DO DINHEIRO \\
\hline PETRK46 & 16,50 & 1,15 & 0,80 & 0,35 & DENTRO DO DINHEIRO \\
\hline PETRK26 & 16,00 & 1,52 & 1,30 & 0,22 & DENTRO DO DINHEIRO \\
\hline PETRK45 & 15,50 & 1,93 & 1,80 & 0,13 & DENTRO DO DINHEIRO \\
\hline PETRK150 & 15,00 & 2,38 & 2,30 & 0,08 & DENTRO DO DINHEIRO \\
\hline
\end{tabular}

Fonte: Os autores.

Questão 3: Considerando a estratégia de remuneração da carteira de ações apresentada por João Paulo, por que ele sugere a Rafael que escolha strikes fora do dinheiro?

Dentro dos contratos de opções podem ser utilizadas tanto estratégias de hedge como de alavancagem. Por exemplo, o investidor que compra uma opção de compra está alavancando seu capital na expectativa da alta do preço da ação porque visa um cenário positivo futuro. Na mesma operação ele poderia estar buscando um hedge para uma posição vendida na ação. Do outro lado o investidor que compra uma opção de venda acredita que o mercado entrará em tendência de baixa, e pode ou buscar uma alavancagem do resultado potencial de queda do preço da ação, ou efetivar um hedge para uma posição já comprada na ação (AZEVEDO, 2011).

Existem inúmeras estratégias diferentes de operar ao mesmo tempo com uma opção e a ação correspondente. Dentre elas podemos citar a venda coberta de opção, geralmente é feita com uma posição comprada no ativo, mas vendido na opção do ativo correspondente, sempre na mesma proporção, porém fora do dinheiro (OTM) (Hull, 2016). Exatamente a maneira a qual JP instriui Rafael, manter as ações PETR em carteira e realizar e venda de CALL na mesma quantidade, assim caso fosse exercido, teria os respectivos ativos para entregar.

Especificamente no caso da estratéfica de remuneração de opções, a intenção da escolha de uma opção fora do dinheiro se dá pela expectativa de não exercício, ou seja, que no momento do exercício o strike seja maior que o spot, assim o investidor fica com o prêmio obtido com a venda de CALL. Azevedo (2011) evidencia que este tipo de operação pode ser melhor implantada a posições curtas de no máximo dois meses. Ademais, o investidor pode vender opções fora do dinheiro com o intuito de auferir o custo de carregamento do CDI da ação-objeto mensalmente.

Questão 4: Ao analisar a estratégia recomendada podemos afirmar que a compra de determinado ativo e a venda de uma opção de CALL do mesmo ativo seria o mesmo que vender uma opção de put? Porque seria mais interessante criar a opção de PUT sinteticamente do que compra-la no mercado?

A criação de uma opção de put sinteticamente ao invés da compra no mercado pode ser justificada por duas principais razões. Primeiramente as opções nem sempre possuem a 
liquidez para absorver as transações necessárias pelos gestores de fundos. Em segundo lugar, gestores de fundos muitas vezes necessitam de preços de strike e datas de exercício diferentes daquelas disponíveis no mercado. (HULL, 2016)

A intenção de Rafael nãe era necessariamente assegurar seu portifólio comprando uma PUT, caso tivesse feito esta escolha, ele estaria pagando para adiquirir um direito de venda do seu ativo. Seu objetivo era vender CALL principalmente pelo prêmio que, como lançador da opção, estaria recebendo. Porém lembrando que ao vender uma $C A L L$, ele estaria vendendo um direito, ou seja, caso o strike esteja menor que o spot, ele não teria a escolha de exercer ou não, este direito estaria nas mãos de quem comprou a opção por ele vendida.

\section{REFERÊNCIAS}

AZEVEDO, H. Investimentos no mercado de opções sobre ações no Brasil: teoria e prática. Rio de Janeiro: Elsevier, 2010.

BODIE, Z.; KANE, A.; MARCUS, A. J. Investimentos. 8. ed. São Paulo: McGraw-Hill Artmed, 2014.

GARNER, C.; BRITTAIN, P. Commodity options: Trading and hedging volatility in the world's most lucrative market. New Jersey. Pearson Education, 2009.

HULL, J. C. Opções, futuros e outros derivativos. 9. ed. São Paulo: Bookman, 2016.

LEMOS, F. Análise técnica dos mercados financeiros: um guia completo e definitivo dos métodos de negociação de ativos. São Paulo: Saraiva Educação, 2015.

MAUAD, R. P. Invista em ações controlando seu risco. São Paulo: Editora Biblioteca 24 Horas, 2015.

RAMOS, C. Derivativos: do tradicional ao exótico. São Paulo: Ed. do Autor, 2018.

SILVA NETO, L. A. Derivativos: definições, emprego e risco. 5. ed. São Paulo: [s.n.], 2016.

\section{BIBLIOGRAFIAS RECOMENDADAS}

Recomenda-se que o aluno leia o ebook gratuito disponibilizado pelo site Infomoney e elaborado pelo analista Fernando Góes;

GOES, F. Acesso em: <https://educação.infomoney.com.br/ebook-opcoes/inscricao.html

Recomenda-se também, para maior compreensão do funcionamento das opções e seu método de precificação, os vídeos disponíveis no YouTube no canal Neologica, principalmente o intitulado - " Opções: o que eles não querem que você saiba”.

Além disso, recomenda-se o uso das seguintes referências bibliográficas:

ASSAF NETO, Alexandre. Mercado Financeiro. 11. ed. São Paulo: Atlas, 2012. 
ECHAUST, Krzysztof. How firms can hedge against market risk. Studies in logic, grammar and rhetoric, [s.I.], v. 37, n. 1, p. 39-49, Bialystok, 2014. DOI:

https://doi.org/10.2478/slgr-2014-0016

FARHI, Maryse. Derivativos financeiros: hedge, especulação e arbitragem. Economia e Sociedade, [S.I.], v. 8, n. 2, p. 93-114, jan. Campinas, 2016.

GUIMARÃES, D. P. G.; ARAUJO, G. S.; BARBEDO, C. H. S. É possível bater o lbovespa com operações de análise técnica no mercado futuro? RAC, v. 15, n. 5, p. 918-930, 2011.

LIMA, Luiz Antônio de Oliveira. Auge e declínio da hipótese dos mercados eficientes. Revista de Economia Política, v. 23, n. 4, p.28-42, dez. São Paulo, 2003.

RABELO JUNIOR, T. S.; IKEDA, R. H. Mercados eficientes e arbitragem: um estudo sob o enfoque das finanças comportamentais. Revista Contabilidade \& Finanças. V. 15, n. 34, p. $97-$ 107, Apr. São Paulo, 2004. 